\title{
Editorial
}

\section{The hand-arm vibration syndrome: an update}

The recently released National Institute for Occupational Safety and Health (NIOSH) criteria document on occupational exposure to hand-arm vibration $^{1}$ reminds us once again that this hazard to workers remains because we have no satisfactory safety standards. Until more epidemiological data become available no exposure level can be recommended by NIOSH. The control recommendations, including medical monitoring, are designed to prevent workers who use vibrating tools from developing signs and symptoms of stage 1 hand-arm vibration syndrome (HAVS) during a working lifetime.

The Taylor-Pelmear scale devised in 1968 for assessing the injury level of HAVS was a simple classification of clinical stage based on a subjective history of tingling, numbness, blanching of digits, and interference with work, domestic, and leisure activities because of loss of manual dexterity. In the 1970s tests were introduced (light touch, pain, temperature appreciation, cold provocation, aesthesiometry, and vibrotactile threshold measurements) to verify the diagnosis and stage. In the 1980 s the importance of the sensorineural component in loss of manual dexterity led to a revision of the TaylorPelmear scale. After an international workshop the Stockholm scale was devised to provide separatenamely, vascular ${ }^{2}$ and sensorineural ${ }^{3}$-classifications. On this scale the loss of dexterity is measured in terms of neurological dysfunction of the periphery, and the "seasonal factor" (more blanching attacks in the winter) in the vascular grading is eliminated. In support of this revision is the increasing evidence that the injury to arteries and nerves in the fingers may be proceeding independently.

For any grading system it is essential to establish objective tests for vascular, sensory, and musculoskeletal damage. Attempts in the past to develop a single objective test were inevitably unsuccessful. With multiple tests clinicians find that the accuracy of assessment of the stage reached is increased and a more scientific base is established provided the tests have good specificity and sensitivity. For tests with a sensitivity as low as $60 \%$, reliability is improved by first establishing a baseline to which prospective measurements at specific intervals can be referred. This applies especially to aesthesiometric and vibrotactile tests of sensorineural impairment, the recognition of which also means that clinicians have to distinguish neural damage induced by vibration from other peripheral neuropathies such as carpal tunnel syndrome with which it is often associated. For medicolegal purposes tests of motor and sensory nerve conduction will be required in addition to the Phalen and Tinel screening tests.

Progress in establishing standardised objective tests has been impeded in the United Kingdom because of a lack of facilities with specialised instrumentation for the evaluation of patients with hand-arm vibration syndrome. In contrast, the Ministry of Labour in Ontario has established, under the chief physician, a laboratory specifically for the vascular and neurological evaluation of patients with HAVS. The clinical findings are correlated with vibration measurements in the workplace and dose response relations are being derived.

In the United Kingdom, as with occupational deafness, the concept of setting up specialist centres distinct from the NHS has been rejected on the grounds of cost and the difficulty of recruiting competent staff. This needs to be reconsidered urgently as compensation claims for HAVS now exceed those due to occupational deafness. The lack of competent examiners is a major disadvantage in court hearings and for assessments of compensation.

Dose effect relations and vibration standards During the first half of the 20th century instrumentation for measurement of vibration, high speed computers for Fourier spectrum analysis, and elaborate data recording systems were unavailable. Data from impact percussive pneumatic tools such as jack hammers, drills, chipping hammers, and scalers became available only in the late 1970 s and 80 s. A knowledge of the degree of vibration gave impetus to dose effect equations, which were then incorporated into the major standards and guides. ${ }^{4-7}$ Establishing safe limits first began in 1955 in Soviet Russia. Subsequently limits were influenced by laboratory experiments in Czechoslovakia and Japan, which indicated that as the vibration frequency signal decreased the subjective response (intolerable; stressful; uncomfortable) increased. Thus a subjective "weighted" frequency curve was introduced into all vibration measurements in the early 1970 s and is still used. Recent studies of workers exposed to vibration at frequencies from $1-5 \mathrm{kHz}$ have shown higher prevalences of HAVS than those predicted 
from the most recent standards and guides mentioned above. Because of these findings and other inconsistencies, it is now recommended by NIOSH that both "weighted" and "unweighted" measurements up to $5 \mathrm{kHz}$ be obtained in all future studies. Whereas engineers, hygienists, and physicists play an essential part in providing dose data on vibrationfor without these a dose effect relation cannot be established-the classification of stage and opinion on prognosis for HAVS must remain with physicians.

\section{Research and policy needs}

In the United Kingdom the academic base for research into occupational medicine has been severely curtailed. This is difficult to understand-in a society increasingly concerned with the environment and the quality of working life-when viewed against the "golden age" of the first 50 years of this century. During this time we had major contributions from Hunter, Lane, Scott, Schilling, Browne, Mair, Lee, and McCallum from the medical schools of universities in London, Manchester, Newcastle, and Dundee on diseases of occupation. As we enter the last decade of the century there is an urgent need to fill the many gaps in our knowledge of HAVS including the fundamental mechanisms by which vibration causes injury to digital arteries, nerves, subcutaneous tissue, muscles, tendons, and possibly bone. The components of the vibration stimulus (frequency, amplitude, impulsiveness) have not yet been related to the damaged hand structures. Furthermore, the degree of damage in terms of stages has not been universally adopted due to the lack of objective tests. Previously the worker's subjective occupational history was the sole criterion for diagnosis of vibration injury. To add to the difficulty of occupational health physicians supervising populations exposed to vibration, there have been conflicting judgements in common law claims for compensation depending on the way in which different judges have approached the question of employers' liability for the hazard, the date of knowledge of the hazard, and the amount of damages. That there would be confusion in the judiciary today could have been forecast from the interval of 35 years between first considering HAVS as a prescribed disease in 1950 to its final prescription in April 1985. During this period the Industrial Injuries Advisory Council issued reports in 1955, 1970, 1975, and 1981. The difficulties outlined in these reports are still present today-namely, the differential diagnosis, especially from carpal tunnel syndrome; establishing an accurate stage classification in the absence of standardised objective tests; establishing a dose effect, that is, relating total and type of vibration to pathology of the hands ${ }^{8}$; and whether various psychosomatic signs and symptoms referable to the central nervous sys- tem could arise from peripheral hand vibration, a line of research vigorously pursued in Soviet Russia $\stackrel{ }{2}$ and subsequently in Japan. So far there are no convincing hard data to support the view of permanent damage to the hypothalamus or other autonomic centres in the central nervous system arising from peripheral hand-arm vibration exposure. ${ }^{10}$

\section{The future}

At present there is an increasing strain being placed on consultant physicians, vascular and orthopaedic surgeons, neurologists, and company doctors. This is due to the late introduction of antivibration design techniques, particularly for pneumatic percussive tools. Because of the use of such techniques, albeit belated, and limitation of exposure. HAVS should become self limiting within 10 to 20 years. As with noise induced deafness before ear protection, the period for prospective epidemiological surveys is limited to this interval. Firstly, little progress can be made until finance becomes available, and the priority is for instrumentation to assess the vascular, sensorineural, and musculoskeletal components. Secondly, epidemiological studies are required to compare vibration spectra of different tools and the resultant prevalences of HAVS. Thirdly, there are no hard data on the reversibility of HAVS after remova of the vibration stimulus nor on the response to treatment although there is some evidence of revero sibility of vasospasm of the digital arteries in the under 50 age group when the vibration stimulus is withdrawn. The view at present is that the sensorineural component is irreversible. Finally, there is the difficult question confronting all occupational physicians; when to remove severe or advanced cases of HAVS from further exposure to vibration. In the United Kingdom there has been no guidance from the Health and Safety Executive. From HAVS case law it would be advisable, in view of the fact that HAVS is a progressive disorder, to prevent subjects from proceeding beyond stage 3 or a rapidly deteriorating stage 2 . The recent NIOSH criteria document ${ }^{1}$ recommends that workers who develop stage 2 HAVS be removed from further exposure to vibration until they are free from signs and symptoms of HAVS. This is based on the data already available on the reversibility of HAVS. The NIOSH document, having failed to establish a recommended exposure level for vibration, has transferred the control of populations exposed to vibration from an emphasis on a vibration standard to the medical monitoring of workers. The suggested NIOSH programme includes (a) a preplacement medical examination with the attention focused on peripheral vascular and neural factors; (b) yearly or more frequent examinations to detect HAVS in the early reversible stage; (c) an open channel of communication with the workers; and (d) the removal of subjects with stage 2 
disease. In the meantime tool manufacturers will be required to reduce vibration to the limits recommended by the published standards and guides. For example, the American Conference of Governmental Industrial Hygienists (ACGIH) calls for a Threshold Limit Value of no more than $4 \mathrm{~m} / \mathrm{s}^{2}$ for a four to eight hour working day using the "weighted" exposure curve covering the frequency range $8-1500 \mathrm{~Hz}$. Looking further ahead a European Economic Community directive $(89 / 392 / \mathrm{EEC})$ on the safety of machines calls for a weighted root mean square acceleration value to which arms are subjected of 2.5 $\mathrm{m} / \mathrm{s}^{2}$. This directive will have the force of law within the member states from July 1990 . Tools will have to have measured vibration values specified in the notice of instruction and also in the sales information. Thus the present situation calls for a major effort to reduce HAVS by controlling vibration at source, and so prevent an occupational hazard first reported in 1911.

Nether Banks,

W TAYLOR

Watten, Wick,

Caithness KW1 $5 X J$, Scotland.

Director, Health and Safety Support Services,

P L PELMEAR

Ministry of Labour (Province of Ontario) 400 University Avenue,

Toronto, Ontario M7A 1T7, Canada.
1 Criteria Document for a recommended standard occupational exposure to hand-arm vibration. Cincinnati: Department of Health and Human Services, 1989. (No 89-106.)

2 Gemne G, Pyykkö I, Taylor W, Pelmear PL. The Stockholm workshop scale for the classification of cold-induced Raynaud's Phenomenon in the hand-arm vibration syndrome (revision of the Taylor-Pelmear scale). Scand J Work Environ Health 1987;13:275-8.

3 Brammer AJ, Taylor W, Peircy JE. Assessing the severity of the neurological component of the hand-arm vibration syndrome. Scand JWork Environ Health 1986;12:428-31.

4 International Organisation for Standardisation. Mechanical vibration-guidelines for the measurement and the assessment of human exposure to hand-transmitted vibration. Geneva: International Organisation for Standardisation, 1986. (ISO 5349.)

5 British Standard Guide to measurement and evaluation of human exposure to vibration transmitted to the hand. London: British Standards Institution, 2 Park St, London W1A 2BS, 1987. (BS 6842.)

6 American National Standards Institute. 1986. (ANSI 5334.)

7 Threshold limit values for chemical substances and physical agents. Indices with intended changes 1989-1990. American conference of governmental industrial hygienists, 1990. (6500 Glenway Avenue, Cincinnati, 45211-4438.)

8 Starck J, Pekkarinen J, Pyykkö I. Physical characteristics of vibration in relation to vibration-induced white finger. $\mathrm{Am}$ Ind Hyg Assoc J 1990;51:179-84.

9 Hand-arm vibration and the central autonomic nervous system. In: Gemne G, Taylor W, eds. Proceedings Symposium. London: Multi-Science Publishing, 1983.

10 Okada A. Pathogenic mechanism of vibration-induced white finger (VWF). In: Okada A, Taylor W, Dupuis $\mathrm{H}$, eds. Handarm vibration. Proceedings of the 5th International Hand Arm Conference. Kanazawa, Japan: Kyoei Press, 1990.

\section{Correspondence and editorials}

The British Journal of Industrial Medicine welcomes correspondence relating to any of the material appearing in the journal. Results from preliminary or small scale studies may also be published in the correspondence column if this seems appropriate. Letters should be not more than 500 words in length and contain a minimum of references. Tables and figures should be kept to an absolute minimum. Letters are accepted on the understanding that they may be subject to editorial revision and shortening.

The journal now also publishes editorials which are normally specially commissioned. The Editor welcomes suggestions regarding suitable topics; those wishing to submit an editorial, however, should do so only after discussion with the Editor. 